\title{
LASER SCANNING AND POINT CLOUD SEGMENTATION FOR CONTACTLESS GEO- MECHANICAL SURVEYING: CONSERVATIVE RESTORATION IN HYPOGEUM ENVIRONMENT.
}

\author{
F. Mugnai ${ }^{1 *}$ \\ ${ }^{1}$ DICEA - Dept. of Civil and Environmental Engineering, Uniersity of Florence, Via di S. Marta 3, 50139 - Florence, Italy - \\ francesco.mugnai@unifi.it
}

KEY WORDS: Laser Scanning; Conservative Restoration; geometrical reconstruction; 3D kinematic analysis; Point Clouds.

\section{ABSTRACT:}

The work presents a survey campaign specifically designed to formulate an effective restoration project in a Cultural Heritage context, the Military Shrine in Cima Grappa (Italy). Several outputs have been generated by exploring the most advanced laser scanning survey technique and some specific point cloud analysis algorithms. A detailed geometrical 3D reconstruction of humanmade and natural tunnels coating materials, a geo-mechanical survey of the rock mass, a map of rock collapses and cinematic analysis of instability processes.

Integrating Laser Scanning technique with the Scan-line survey allowed to perform advanced analysis and rock-mass characterisation in a predominant subterranean developed area. Most of the tunnels and underground spaces displayed rock collapses and diffuse active instability processes that certainly could have drastically slowed down surveys and analysis. The adopted techniques allowed both to proceed in acquiring data end in delivering sound outputs rapidly.

\section{INTRODUCTION}

Promoted and financed by the Italian Presidency of the Council of the Ministers and the Italian Ministry of Defence, the restoration project insists on a mountain area on the top of Monte Grappa, also called "Cima del Grappa", Italy. The area of interest, represented by the coloured point cloud in figure 1 , is accessible from the main gate in correspondence of Caserma Milano (Milano Barrack), end it is mainly composed by narrow underground tunnels (Figure 2).

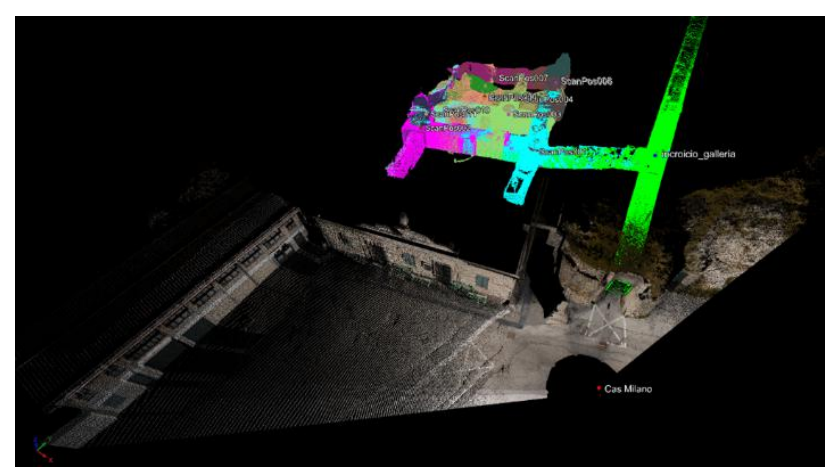

Figure 1. Aerial Orthophoto of the studied area

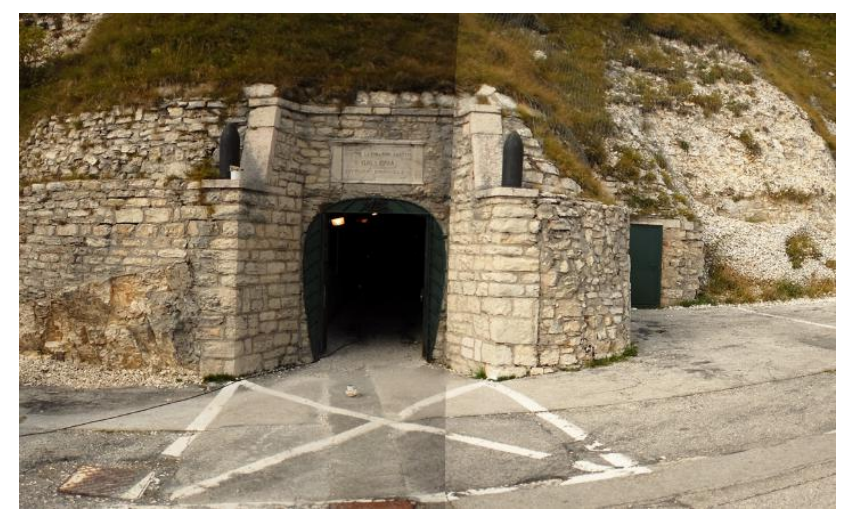

Figure 2. Main entrance of Vittorio Emanuele III gallery.

The underground area is mainly composed by intensively jointed limestone rock-mass (Figure 3-4). Some recovery interventions have been executed in the past to stabilize circumscribed vertical collapses (Figure5), some other to stabilize ceiling vaults. Several rock collapses have occurred in the underground infirmary environment and the access tunnels during the last few years. This paper follows a well-established path (Bitelli et al., 2017; Bonora et al., 2003; Castagnetti et al., 2012; Chías Navarro et al., 2017; Grussenmeyer et al., 2012; Oreni et al., 2006) of using remote Sensing and 3D surveys techniques (Assi et al., 2019; Kuester \& Chang, 2010; Remondino, 2011; Remondino et al., 2011; Thiel \& Wehr, 2004; Várady et al., 2007; Wagner et al., 2006) to support out of the ordinary conservative restoration projects in a complex work environment (Brutto et al., 2017; Guidi et al., 2014; Spangher et al., 2017; Tucci et al., 2016). Therefore, performing a detailed

\footnotetext{
* Corresponding author
} 
geo-mechanical characterisation of the former infirmary underground area has been necessary to plan specific consolidating interventions properly.
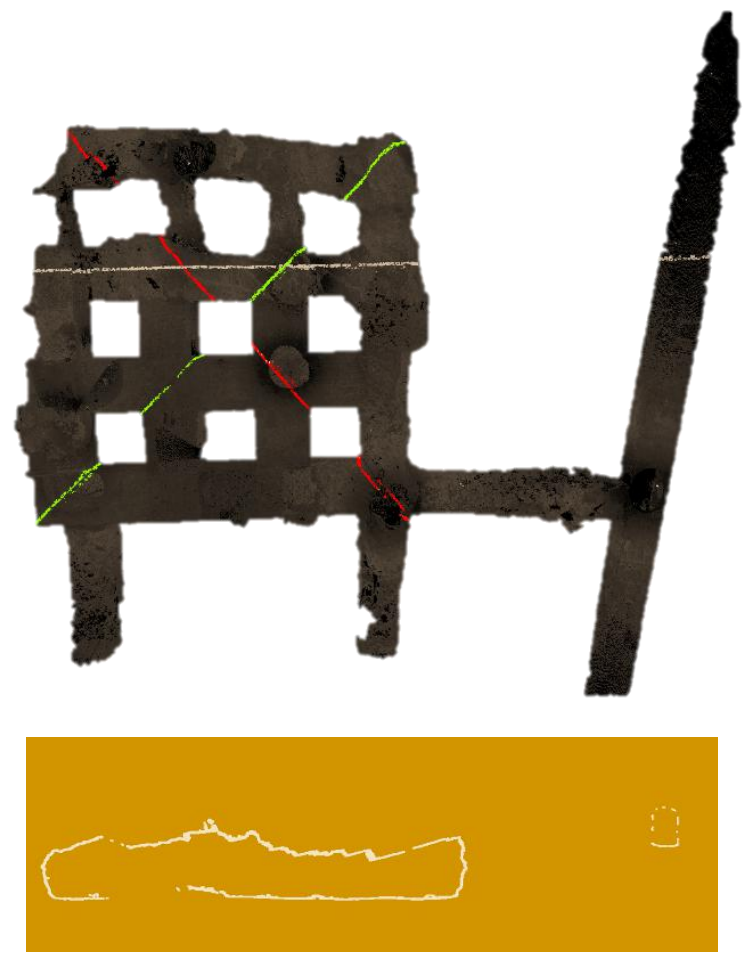

Figure 3. Nadiral view (top) and section profile (bottom) of the former infirmary study area.

For this purpose, a high-resolution laser scan survey has been performed, and 3D meshes of the area have been extracted. By automatically extracting rock-mass characteristics (surface orientation, number of cracks, spacing, frequency of cracks), the traditional geo-mechanical survey has been improved (Bolkas et al., 2018; Feng \& Röshoff, 2015; Jaboyedoff et al., 2007; Riquelme et al., 2018) and extended to the whole formerinfirmary area.

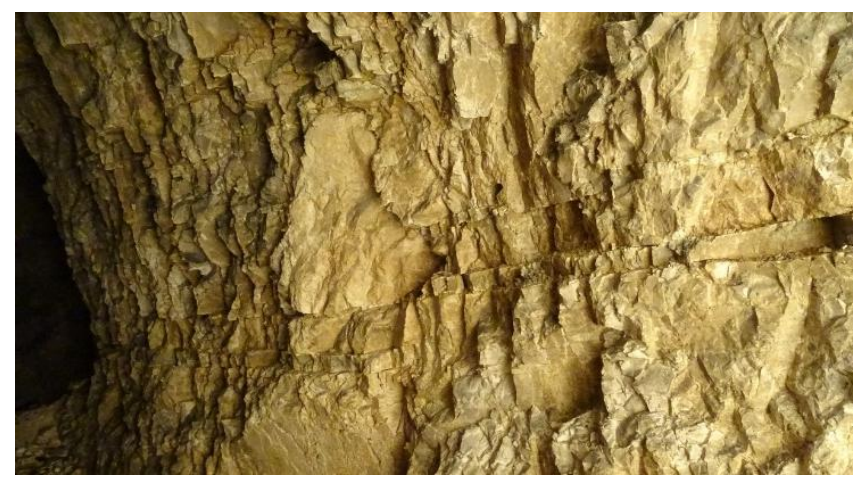

Figure 4. View of rock outcrop within the infirmary tunnel.

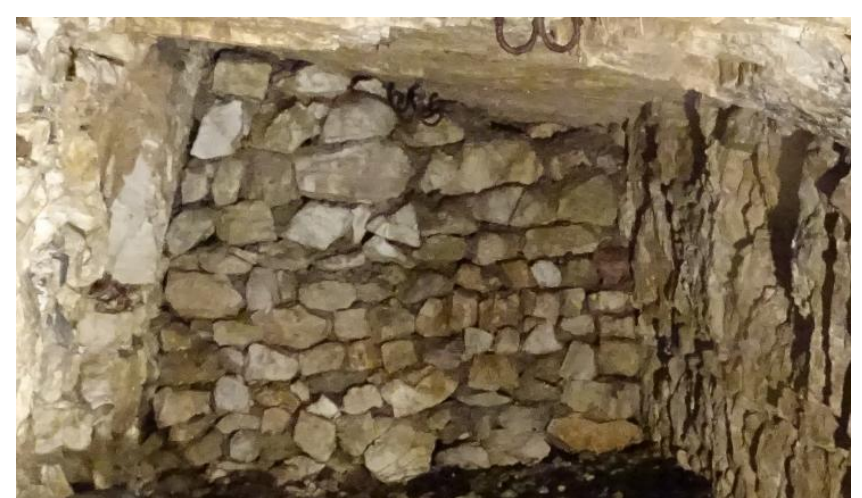

Figure 5. View of rock outcrop within the infirmary tunnel.

\section{MATERIALS AND METHODS}

Both laser scanning and classic manual geo-mechanical survey have been carried out to perform the rock-mass geo-mechanical characterization and the $3 \mathrm{D}$ kinematic analysis.

In correspondence of not accessible and prone to collapsing areas, the classic geo-mechanical survey (scan-line detection method. citation) of the rock mass has been substituted with measures obtained from Laser Scanning datasets. In particular, the obtained results of the geo-mechanical analysis were thus combined with the analysis of the point clouds acquired by the laser scanner.

\section{Laser Scanning acquisition Campaign}

A Riegl LMS-Z420i laser scanner model has been employed to perform the acquisition campaign. A total of over 40 million points were thus acquired. Before proceeding with laser scanning acquisition, some targets/reflectors were positioned within the scene.

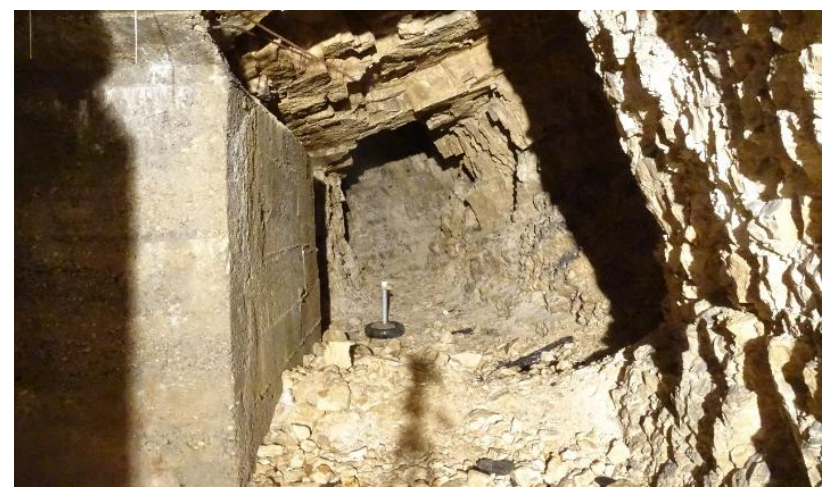

Figure 6. Tunnel area, Scan position $n^{\circ} 3$.

\section{Scan Line Survey}

A scan line survey consists in acquiring, through a manually performed measurements, some rock-mass' geometrical characteristics such as cracks orientation, number of families of discontinuity, spacing, persistence, opening, roughness, surface re-sistance, degradation, filling, and filtration. If, from one side, it is a well-established method and leads to accurate rock-mass characterizations, from the other side it is time consuming and implies presence of operators on site for a long time. 


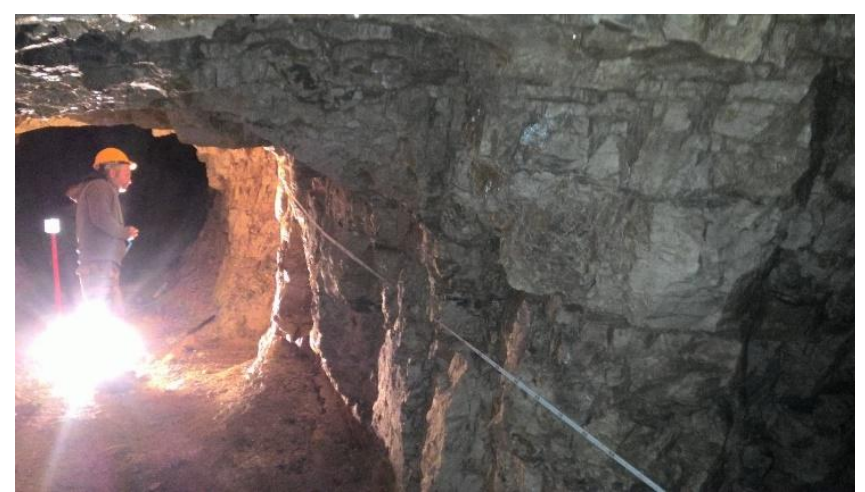

Figure 7. View of rock outcrop within the infirmary tunnel.

\section{$3 D$ kinematic stability analysis of the rock mass}

The data obtained from the geo-mechanical characterisation of both the intact rock, discontinuity system, and the rock mass were used to carry out a 3D kinematic analysis of the rock mass. The stability of the blocks composing a rock mass is essentially controlled by the discontinuities' geometric and geo-mechanical properties. The term "kinematic analysis" refers to analyzing blocks of the rock's behaviour under their weight and with purely attractive sliding resistance along the discontinuity surfaces (Bieniawski, 1989; Canon Europe, 2020; Hoek \& Bray, 1981).

A quantitative approach can be pursued by defining a kinematic hazard index for each kinematic mechanism, which expresses the relative probability that a given mecha-nism failure may occur based on the structural and geo-mechanical conditions of the rock mass. Such indexes can be calculated by counting the following quantities:

$\mathrm{Npf}=$ number of poles of the discontinuities that satisfy the conditions for planar sliding;

$\mathrm{I}_{\mathrm{wf}}=$ number of the intersections of the discontinuities that satisfy the conditions for the sliding of wedges;

$\mathrm{N}_{\mathrm{bt}}=$ number of the poles of the discontinuities that satisfy the conditions for direct overturning;

$\mathrm{I}_{\mathrm{bt}}=$ number of intersection lines that satisfy the conditions for direct overturning;

$\mathrm{N}_{\mathrm{ft}}=$ number of the poles of the discontinuities that satisfy the conditions for bending overturning.

\begin{tabular}{|c|c|}
\hline $\begin{array}{c}\text { Instability } \\
\text { Mechanism }\end{array}$ & Hazard Index \\
\hline Planar failure & $C_{p f}=\frac{N_{p f}}{N}(\%)$ \\
\hline Wedge failure & $C_{w f}=\frac{I_{w f}}{I}(\%)$ \\
\hline Flexural toppling & $C_{f t}=\frac{N_{f t}}{N}(\%)$ \\
\hline Block toppling & $C_{b t}=\frac{N_{b t}}{N} \cdot \frac{I_{b t}}{L}(\%)$ \\
\hline
\end{tabular}

Table 1. Hazard kinematic indexes [49], $\mathrm{N}=$ number of poles satisfying a specific failure condition; $\mathrm{I}=$ number of intersections satisfying a specific failure condition.

\section{Point Cloud Segmentation}

a semi-automatic segmentation method, DiAna3D, was used to extract geometric characteristics of discontinuities and relative planes. By processing point clouds, some of the rock-mass parameters (Barton et al., 1974; PRIEST, 1993) are block size, the number of sets, persistence, orientation (Figure 7), spacing/frequency (and derived RQD), and scale-dependent roughness can be determined.

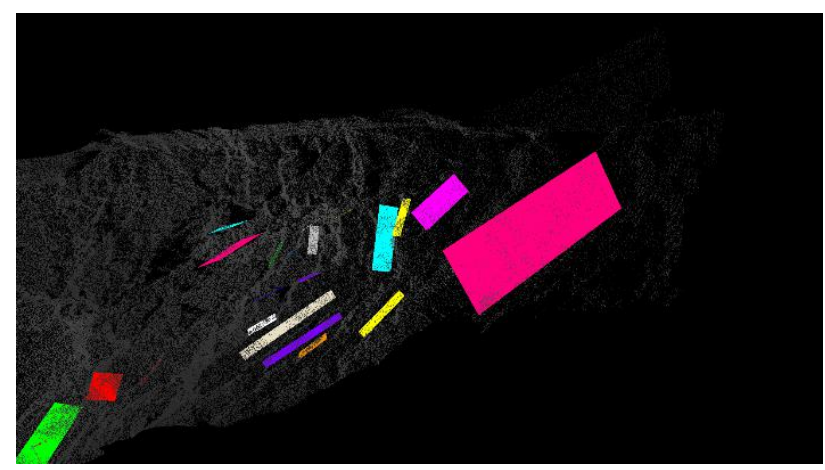

Figure 8. Identified plains on an outcrop's portion point cloud.

As reported in (Mugnai et al., 2021), the method allows to identifying principal plains on the point cloud by applying best fitting planes algorithm through a searching cube which contains a selection of a point cloud subset.

The process consists in three main steps: 1) Organized point clouds were analysed (Figure 9a), looking for the points around which the local geometry is sufficiently planar; progressive germination algorithm that allowed to gradually add all the neighbouring points, co-planar with the initial nucleus (Figure 9b), and to define its external 3D polygon (Figure 9c, d). 3) combining the results obtained from the individual scan positions by eliminating redundancies in the overlapping areas.
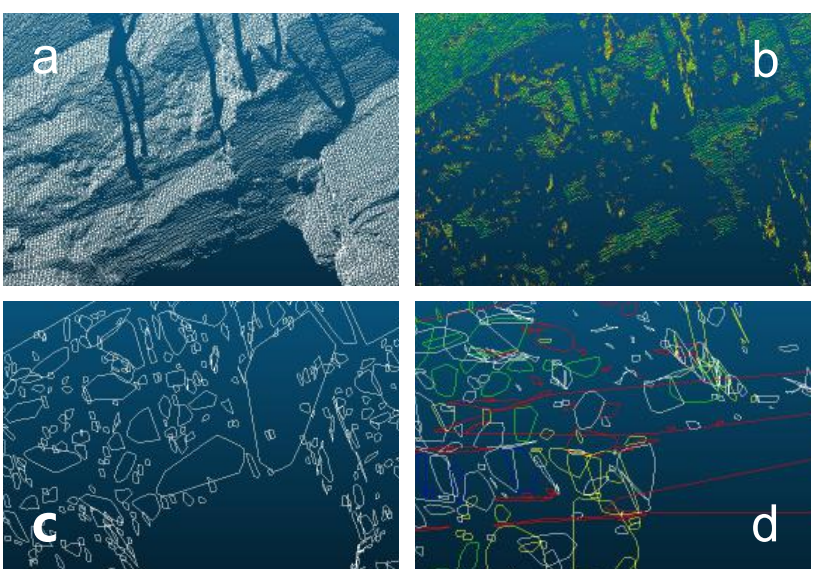

Figure 9. Identified plains on an outcrop's portion point cloud.

\section{Remote geo-mechanical survey}

The traditional geo-mechanical survey is highly limited if the area to be investigated inaccessible or unreachable or, as in the case in question, very articulated and intensely fractured. Thanks to the high spatial resolution of the laser scanning data, it is possible to use point clouds to integrate the traditional survey data and obtain information on the rock mass geometry remotely. 


\begin{tabular}{|c|c|c|c|}
\hline & Plane & DIP Dir & DIP Angle \\
\hline$\square$ & Plane010 & 250.609 & 11.673 \\
\hline$\square$ & Plane011 & 246.964 & 12.239 \\
\hline$\square$ & Plane012 & 270.104 & 10.674 \\
\hline$\square$ & Plane013 & 241.237 & 14.397 \\
\hline$\square$ & Plane014 & 286.716 & 32.23 \\
\hline$\square$ & Plane015 & 257.729 & 12.423 \\
\hline$\square$ & Plane016 & 79.972 & 76.419 \\
\hline$\square$ & Plane017 & 40.558 & 44.121 \\
\hline$\square$ & Plane018 & 356.816 & 80.687 \\
\hline$\square$ & Plane019 & 3.607 & 84.252 \\
\hline$\square$ & Plane020 & 358.88 & 83.758 \\
\hline$\square$ & Plane021 & 356.952 & 68.824 \\
\hline$\square$ & Plane022 & 7.131 & 77.386 \\
\hline$\square$ & Plane023 & 1.736 & 80.393 \\
\hline$\square$ & Plane024 & 10.309 & 77.32 \\
\hline$\square$ & Plane025 & 28.447 & 75.352 \\
\hline$\square$ & Plane026 & 38.77 & 84.682 \\
\hline$\square$ & Plane027 & 356.973 & 84.414 \\
\hline$\square$ & Plane028 & 6.152 & 80.515 \\
\hline$\square$ & Plane029 & 256.401 & 9.901 \\
\hline$\square$ & Plane030 & 241.563 & 16.042 \\
\hline$\square$ & Plane031 & 240.319 & 13.774 \\
\hline$\square$ & Plane032 & 41.746 & 10.481 \\
\hline
\end{tabular}

Table 2. List of the identified plans, Dip Angle and Dip Direction for each plan.

In particular, using a tool developed in the Matlab environment called DiAna (Gigli et al., 2008), the discontinuity plans were identified semi-automatically, and their spatial orientations were calculated.

\section{RESULTS}

Thanks to the performed survey campaigns, a considerable amount of the 3D data of the underground spaces have been obtained. A series of elaborations have been processed, capitalising on the high-resolution point clouds acquired by laser scanning.

The kinematic analyses were carried out on the entire underground study area by applying a new methodology (Dotta et al., 2017) that better suits the complex morphology with large portions of the galleries' walls and vaults. Figure 10 shows the kinematic analysis' results of a portion of rock mass. As described above (Section 2), the probability that a given mechanism failure may occur (Kinematic Index) in correspondence of a certain rock mass area have been calculated and projected on the mesh surface.
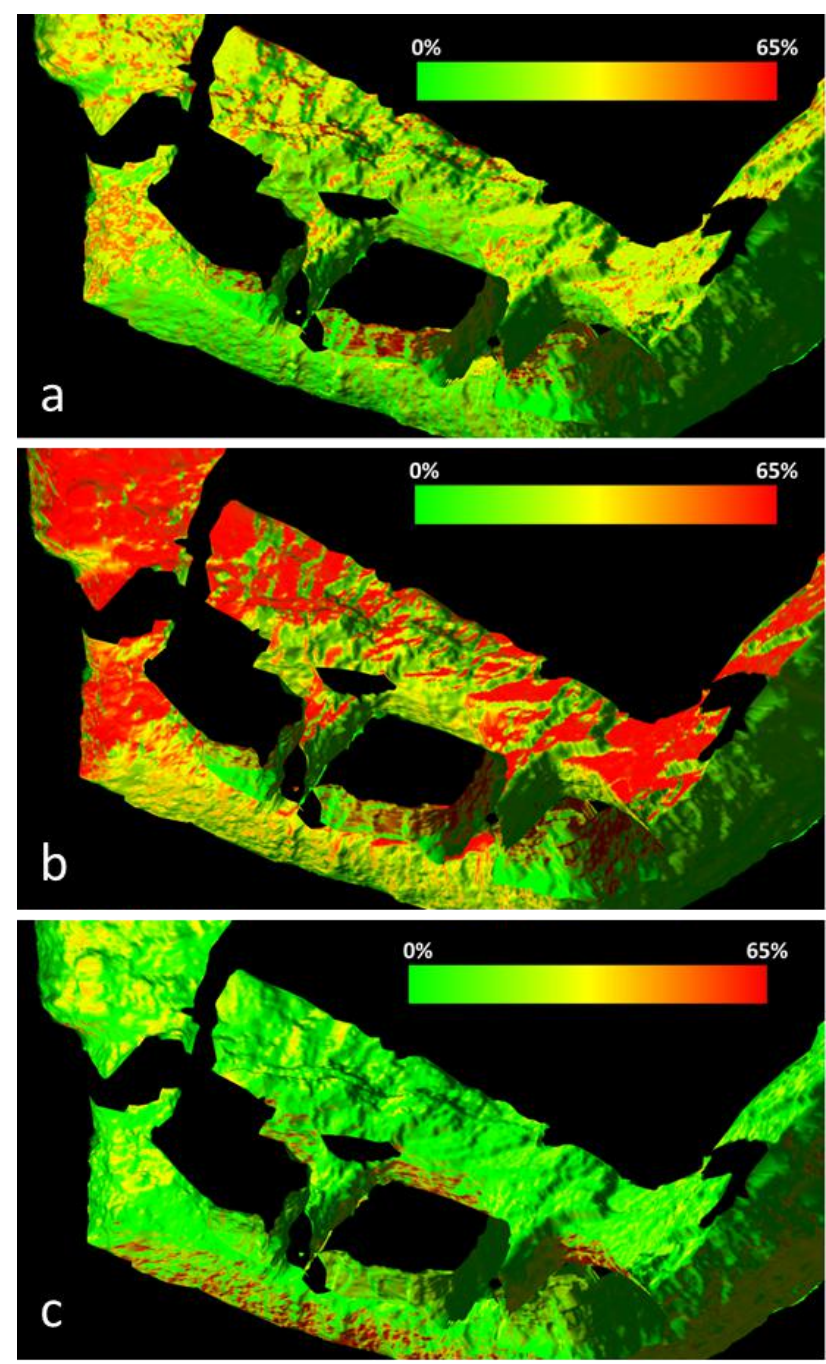

Figure 10. Datail of the Infirmary's 3D Kinematic analysis: a) Planar Failure (PF) mechanism; b) Wedge Failure (WF); c) Toppling Failure (TF).

Figure 11 represents the Global kinematics Indexes (GKI) projected on the overall infirmary area mesh. The Global Kinematic Index is composed by the standard indexes such as PF-WF-TF and the Free Fall (FF) mechanisms, which mainly represents the blocks or bigger portions of rock mass that fall down detaching from the vault and ceiling.

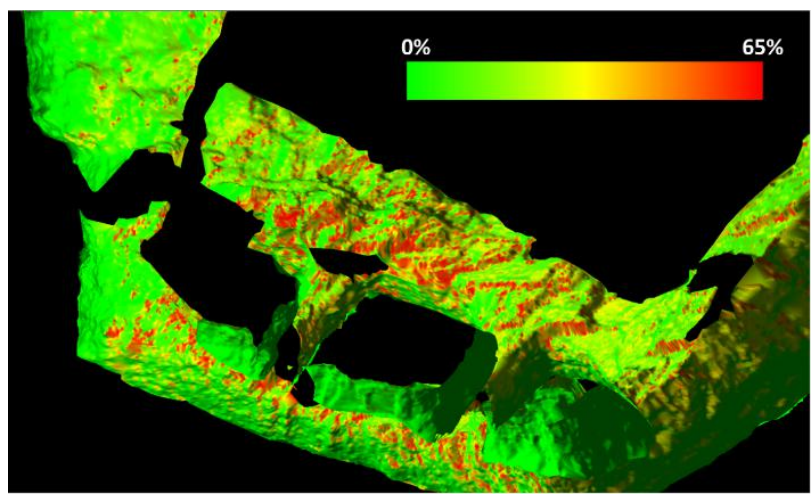

Figure 11. Global Kinematic Index 3D map of the infirmary’s detail. 
Remotely extracted orientations of planes have been measured applying point clouds segmentation and presented within a stereo-plot according to the family of discontinuities they belong to (Fig. 12). By family of discontinuities, we mean the set of discontinuities with a similar orientation (sub-parallels). The set is generally of the same type and, presumably, originating with the same genetic mechanism.
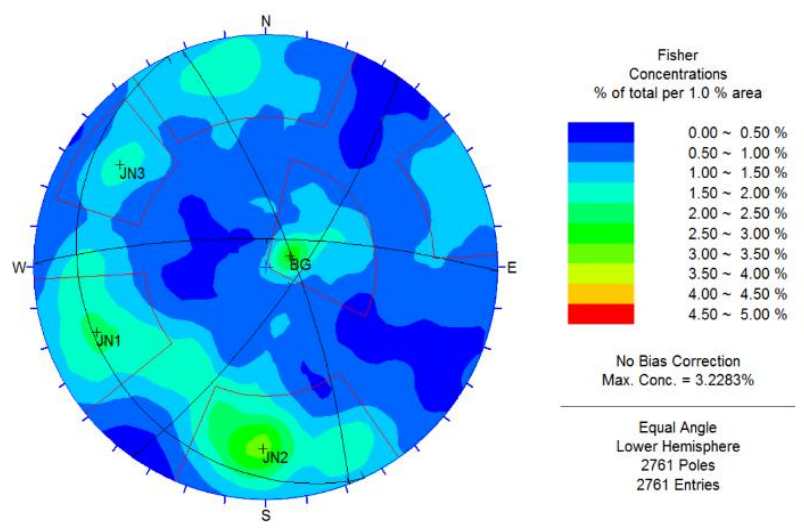

Figure 12. 3D representation of the discontinuity plans remotely extracted and divided by family. White: no family; red: BG; yellow: JN1; green: JN2; blue: JN3.

\section{DISCUSSIONS}

Applying Laser Scanning and advanced survey techniques to perform quantitative analysis on rock mass, leads to some advances. The massive number of observations and data that can be acquired and stored in the same time span, is considerably bigger, if compared with a common manually performed scan-line method. This can be easily appreciated looking at figure 13 and 14; the amount of poles in figure 13, that represents the semi-automatic process identified joints' planes, are many more if compared with the poles showed in figure 14, that represent the poles recorded using the manual method, scan-line survey. It is worth to notice that both results, that outcome from the two different surveying methods, lead to a similar solution: Joint family's orientations have a strong similarity
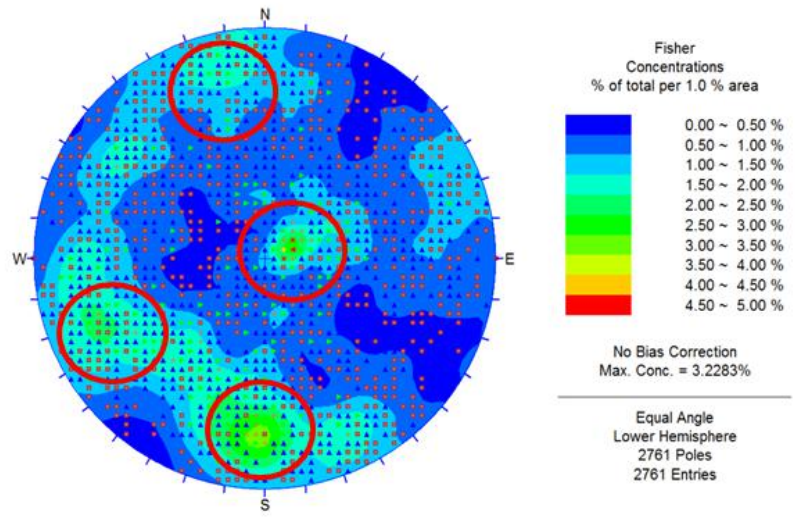

Figure 13. Stereographic projections of the poles' concentration. Red circles highlight the highest poles' concentration obtained by semi-automatic analysis of laser scanning survey.

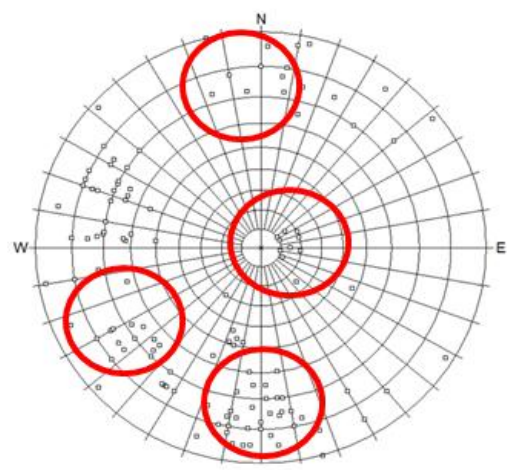

Figure 14. Stereographic projection of poles. Red circles in figure show the highest poles' concentration obtained by analysing the manual (scan-l-ine) survey.

The number of the performed scan-positions for some areas has been quite high. It is partially consequence of the very articulated tunnels' morphology, characterised by many bumps, depressions, and irregularities of the rock mass surface. Indeed, the consequent massive number of shaded areas led to complicated scanning geometries and made designing scan positions effectively a problematic task. The scan position overlapping percentage during the survey varied from 35 to $60 \% .60 \%$ could be generally considered a good value. To completely cover certain areas, several scan positions has been necessary, as showed in figure 14.

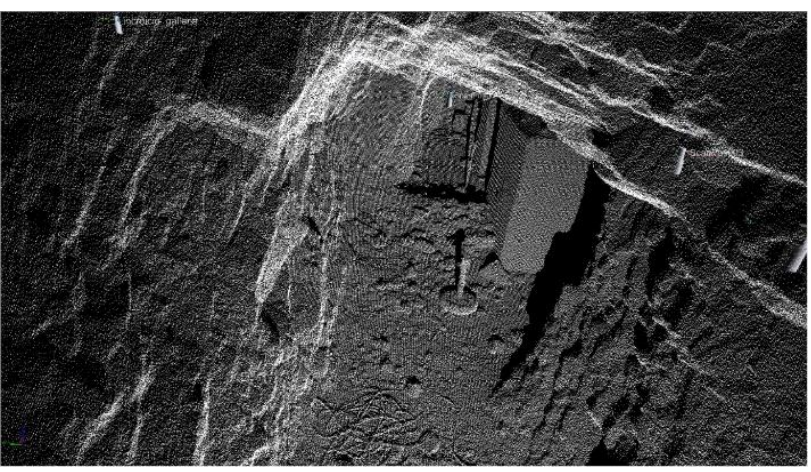

Figure 14. 3D point cloud of the underground area joining point clouds from 4 different scan position.

Since the remote geo-mechanical survey method demonstrated a good reliability

and can

\section{CONCLUSIONS}

Good results can be achieved by using Laser Scanning survey to remotely perform rock mass characterization even in conservative restoration project.

In October 2016 a series of hi-resolution laser scans were collected from 13 different scan positions starting from the square in front of the Milan barracks to completely reconstruct the 3D morphology of the former infirmary. The acquired highresolution point clouds have made it possible to extract the discontinuities that pervade the rock mass dividing it into small blocks. This process, combined with the results of traditional geo-mechanical surveys have allowed us to characterize the rock mass from a quantitative point of view. 
Geo-mechanical and laser scanner surveys were combined and compared as the traditional geo-mechanical survey (scan-line survey) is highly limited since the area to be investigated is inaccessible or unreachable, or, as in the proposed case, very articulated and intensely fractured.

Performing remote geo-mechanical survey allowed to carry out a high quality geo-mechanical rock-mass characterization in a very short time, if compared to the traditional method, and to maintain the survey activities under an acceptable level of risk exposure. Although Laser Scanning dataset needs a further post processing effort to reach outcomes comparable with a scan-line survey, the time span under which operators are exposed to risk remain much shorter than using the ordinary scan line method.

Comparing results from traditional scan line surveys and the remote one, in terms of joint family orientations, points out the good reliability of the remote method, even in narrow and unconventional environment as relatively small underground tunnels. Point clouds obtained from the high-resolution laser scanning survey have been exploited to create a detailed 3D model of the area and integrate the traditional geo-mechanical survey with information automatically extracted from the point clouds. The comparison between results from manually acquired joints orientations and the semiautomatic extraction indicates that the applied technique represents an effective alternative to manual surveying, and it allows to reduce operators risk exposition to collapsing event. Finally, the results of the geo-mechanical analysis of the rock mass thus obtained were used to perform a $3 \mathrm{D}$ kinematic analysis aimed at assessing the propensity to failure for the various plausible breaking mechanisms in the tunnel sectors analysed and a GKI 3D map has produced.

\section{REFERENCES}

Assi, R., Landes, T., Murtiyoso, A., \& Grussenmeyer, P. (2019). Assessment of a keypoints detector for the registration of indoor and outdoor heritage point clouds. International Archives of the Photogrammetry, Remote Sensing \& Spatial Information Sciences.

Barton, N., Lien, R., \& Lunde, J. (1974). Engineering classification of rock masses for the design of tunnel support. Rock Mechanics, 6(4), 189-236.

Bieniawski, Z. T. (1989). Engineering rock mass classifications: a complete manual for engineers and geologists in mining, civil, and petroleum engineering. John Wiley \& Sons.

Bitelli, G., Balletti, C., Brumana, R., Barazzetti, L., D'urso, M. G., Rinaudo, F., \& Tucci, G. (2017). Metric documentation of cultural heritage: Research directions from the Italian gamher project.

Bolkas, D., Vazaios, I., Peidou, A., \& Vlachopoulos, N. (2018). Detection of rock discontinuity traces using terrestrial LiDAR data and space-frequency transforms. Geotechnical and Geological Engineering, 36(3), 1745-1765.

Bonora, V., Chieli, A., Spanò, A., Testa, P., \& Tucci, G. (2003). 3D metric-modelling for knowledge and documentation of architectural structures (royal palace in turin). International archives of photogrammetry remote sensing and spatial information sciences, 34(5/w12), 60-65.

Brutto, M. Lo, Sciortino, R., \& Garraffa, A. (2017). RPAS and TLS tecniques for archaeological survey: the case study of the archaeological site of Eraclea Minoa (Italy). The International Archives of Photogrammetry, Remote Sensing and Spatial

\section{Information Sciences, 42, 433.}

Canon Europe. (2020). Techspecs. Manual. https://www.canoneurope.com/for home/product finder/camcorders/high definiti on_hd/legria_hf_g30/specification.html

Castagnetti, C., Bertacchini, E., Capra, A., \& Dubbini, M. (2012). Terrestrial laser scanning for preserving cultural heritage: analysis of geometric anomalies for ancient structures. FIG Working Week 2012-Territory, Environment, and Cultural Heritage, 1-13.

Chías Navarro, P., Abad Balboa, T., Echeverría Valiente, E., Miguel Sánchez, M. de, \& Llorente Zurdo, M. P. (2017). Underground surveying: 16th century cellar vaults in the Galería de Convalecientes, Monastery of San Lorenzo del Escorial.

Dotta, G., Gigli, G., Ferrigno, F., Gabbani, G., Nocentini, M., Lombardi, L., Agostini, A., Nolesini, T., \& Casagli, N. (2017). Geomechanical characterization and stability analysis of the bedrock underlying the Costa Concordia cruise ship. Rock Mechanics and Rock Engineering, 50(9), 2397-2412.

Feng, Q., \& Röshoff, K. (2015). A survey of 3D laser scanning techniques for application to rock mechanics and rock engineering. In The ISRM Suggested Methods for Rock Characterization, Testing and Monitoring: 2007-2014 (pp. 265-293). Springer.

Gigli, G., Mugnai, F., Falorni, G., Manzo, G., Morelli, S., Leoni, L., Lombardi, L., \& Casagli, N. (2008). Integration of terrestrial laser scanning and the Permanent Scatterers technique for instability analyses in urban areas. August 2015.

Grussenmeyer, P., Alby, E., Landes, T., Koehl, M., Guillemin, S., Hullo, J.-F., Assali, P., \& Smigiel, E. (2012). Recording approach of heritage sites based on merging point clouds from high resolution photogrammetry and terrestrial laser scanning. Int. Arch. Photogramm. Remote Sens. Spat. Inf. Sci, 39, 553558.

Guidi, G., Russo, M., \& Angheleddu, D. (2014). 3D survey and virtual reconstruction of archeological sites. Digital Applications in Archaeology and Cultural Heritage, 1(2), 55-69.

Hoek, E., \& Bray, J. D. (1981). Rock slope engineering. CRC Press.

Jaboyedoff, M., Metzger, R., Oppikofer, T., Couture, R., Derron, M.-H., Locat, J., \& Turmel, D. (2007). New insight techniques to analyze rock-slope relief using DEM and 3Dimaging cloud points: COLTOP-3D software. 1st Canada-US Rock Mechanics Symposium.

Kuester, F., \& Chang, B. J. (2010). Asce, SM; Hutchinson, TC; Asce, M. Terrestrial Laser Scanned-Based Structural Damage Assessment. J. Comput. Civ. Eng, 24.

Mugnai, F., Farina, P., \& Tucci, G. (2021). Exploiting a SemiAutomatic Point Cloud Segmentation Method to Improve the Quality of Rock-Mass Characterization. The Cima Grappa Conservative Restoration Case Study. ISPRS International Journal of Geo-Information, 10(5), 276. https://doi.org/10.3390/ijgi10050276

Oreni, D., Fassi, F., Brumana, R., Prandi, F., \& Tuncer, H. (2006). Laser scanning supports architectural mappings and historical urban view analysis. XI International CIPA 
Symposium.

PRIEST, S. D. (1993). The collection and analysis of discontinuity orientation data for engineering design, with examples. In Rock Testing and Site Characterization (pp. 167192). Elsevier.

Remondino, F. (2011). Heritage recording and 3D modeling with photogrammetry and 3D scanning. Remote Sensing, 3(6), $1104-1138$

Remondino, F., Rizzi, A., Jimenez, B., Agugiaro, G., Baratti, G., $\&$ De Amicis, R. (2011). The Etruscans in 3D: From space to underground. Geoinformatics Fce Ctu, 6, 283-290.

Riquelme, A., Tomás, R., Cano, M., Pastor, J. L., \& Abellán, A. (2018). Automatic mapping of discontinuity persistence on rock masses using 3D point clouds. Rock Mechanics and Rock Engineering, 51(10), 3005-3028.

Spangher, A., Visintini, D., Tucci, G., \& Bonora, V. (2017). Geomatic 3d modeling of a statue (also) for structural analysis and risk evaluation: the example of san giovannino martelli in florence. International Archives of the Photogrammetry, Remote Sensing \& Spatial Information Sciences, 42.

Thiel, K. H., \& Wehr, A. (2004). Performance capabilities of laser scanners-an overview and measurement principle analysis. International Archives of Photogrammetry, Remote Sensing and Spatial Information Sciences, 36(8), 14-18.

Tucci, G., Bonora, V., Fiorini, L., \& Conti, A. (2016). The florence baptistery: 3-d survey as a knowledge tool for historical and structural investigations. International Archives of the Photogrammetry, Remote Sensing \& Spatial Information Sciences, 41.

Várady, T., Facello, M. A., \& Terék, Z. (2007). Automatic extraction of surface structures in digital shape reconstruction. Computer-Aided Design, 39(5), 379-388.

Wagner, W., Ullrich, A., Ducic, V., Melzer, T., \& Studnicka, N. (2006). Gaussian decomposition and calibration of a novel small-footprint full-waveform digitising airborne laser scanner. ISPRS Journal of Photogrammetry and Remote Sensing, 60(2), $100-112$. 